\title{
Why is the pipeline leaking? Experiences of young women in STEM vocational education and training and their adjustment strategies
}

Elena Makarova ${ }^{1 * \dagger}$, Belinda Aeschlimann ${ }^{2^{* \dagger}}$ and Walter Herzog ${ }^{3}$

*Correspondence:
elena.makarova@univie.
ac.at; belinda.aeschlimann@
ehb-schweiz.ch
${ }^{+}$Elena Makarova and Belinda
Aeschlimann contributed
equally to the article
'Department of Education,
Centre for Teacher
Education, University
of Vienna, Porzellangasse 4,
1090 Vienna, Austria
${ }^{2}$ Swiss Federal
Institute for Vocational
Education and Training,
Kirchlindachstrasse 79,
Postfach, 3052 Zollikofen,
Switzerland
Full list of author information
is available at the end of the
article
article

\begin{abstract}
Purpose: The paper investigates the perceptions of young women during their vocational education and training (VET) in traditionally male-dominated STEM fieldsscience, technology, engineering, and mathematics—by analyzing mechanisms and actions addressing the female gender in gender-atypical career fields and reveals strategies young women apply when adjusting to the male-dominated educational and professional fields.
\end{abstract}

Design/methodology/approach: The data originate from semi-structured interviews with young women $(N=71)$ who had chosen a STEM career and who were enrolled in VET in Swiss secondary schools.

Results: The results indicate different processes of gendering in VET, uncovering various mechanisms and symbolic actions which contribute to the (re-)production of a masculine culture in STEM professions. Furthermore, the study provides insight into the different strategies young women apply in order to adjust to gender-atypical educational and professional life domains.

Implications: The paper calls for the visibility of gender inequality in VET in order to make changes toward less female dropout in STEM fields. Moreover, the paper also presents implications for HR professionals and practitioners and provides suggestions for debates about the shortage of (female) STEM workers.

Originality/value: Little is known about women's experience in gender-atypical tracks of VET. There is still a need to plug the leaks, i.e., reduce female attrition, in the STEM pipeline.

Keywords: Gender inequality, STEM, Women, Human resource management, Qualitative method

\section{Background}

International attention continues to focus on the shortage of individuals in STEM, especially the lack of women. The gender gap with male dominance in the fields of science, technology, engineering, and mathematics (the so-called STEM subjects) has been well documented across most OECD countries (Jarman et al. 2012; OECD 2009, 2012). In Switzerland, there is still a lack of women in STEM subjects and this shortage appears to be rather stable (Aeschlimann et al. 2015b; SKBF 2014; Sousa-Poza 2003). Women

(C) 2016 Makarova et al. This article is distributed under the terms of the Creative Commons Attribution 4.0 International License (http://creativecommons.org/licenses/by/4.0/), which permits unrestricted use, distribution, and reproduction in any medium, provided you give appropriate credit to the original author(s) and the source, provide a link to the Creative Commons license, and indicate if changes were made. 
are still more likely to choose educational and vocational pathways that lead to service, sales and clerical work (e.g., nurse, hairdresser), while men predominate in production and managerial occupations (e.g., mechanic, electronic technician) (Charles 1992; Hadjar and Aeschlimann 2015).

Nosek et al. (2002) have also shown that women who choose a STEM course of study experience a mismatch with their chosen field. Moreover, even those women who receive STEM degrees are less likely to choose STEM careers compared to males with STEM degrees (Beede et al. 2011; Ceci et al. 2009). Among women who go into STEM fields, nearly twice as many leave their field than do men (Preston 2004). To address the fact that the proportion of women in the STEM occupational fields decreases continuously through the educational and vocational tracks, from elementary school to initial employment and professional career, scholars use the metaphor of a leaking pipeline (e.g., Burke and Mattis 2007; Etzkowitz et al. 2000; Solga and Pfahl 2009). Passing through STEM career pathways women drop out remarkably more often than men, resulting in a much smaller proportion of women at the end of the pipeline. It is, therefore, crucial to improve our understanding of women's experiences as they proceed along genderatypical career pathways, especially those which may lead to their decision to drop out of the pipeline of male-dominated STEM professions.

In order to better understand the gender gap in STEM careers, our study focuses on young women's experiences during their vocational education and training (VET) in career fields traditionally dominated by men. Our study has two aims: Firstly, our goal is to analyze mechanisms and actions that address the female gender in the gender-atypical career fields. Secondly, we study strategies young women apply when adjusting to the male-dominated educational and professional fields. Our results allow us to draw some conclusions for human resource management.

The paper proceeds as follows. Section "Gender and distinct career pathways of women and men" discusses the theoretical and empirical background of our study. Section "Focus of the study" introduces the study focus. Section "Methods" describes the methodology used in the study. Section "Results" presents the empirical results related to the research questions. Finally, we discuss our findings and draw conclusions in section "Discussion and conclusion".

\section{Gender and distinct career pathways of women and men Theoretical approaches}

Gender stereotypes and gender roles

As a part of a societally shared belief system, gender stereotypes influence perceptions of both sexes in a bipolar mode implying that what is masculine is not feminine and vice versa. Moreover, the stereotypical beliefs about sexes are not only descriptive, but also prescriptive (Deaux and LaFrance 1998; Heilman and Parks-Stamm 2007; Rudman and Phelan 2007). While a descriptive component of stereotypical gender beliefs reveals "how men and women typically are perceived" a prescriptive component "reflects how men and women 'should be' and, importantly, how they 'should not be"' (Rudman and Phelan 2007, p. 24).

This belief system is shaped in large part through socio-cultural expectations, which include attitudes toward female and male societal roles, female and male occupational 
types and gender-associated perceptions of the self (Deaux and LaFrance 1998; Eagly and Wood 1999). Social role theory argues that societally shared beliefs about female and male 'roles' are conveyed through the socialization process and preserved through "psychological processes that stabilize these societal practices by making them seem natural and inevitable to members of the society" (Eagly and Wood 2011, p. 765). Societal roles of women and men, thus, reinforce gender stereotypes "by which each sex is expected to have characteristics that equip it to function adequately in its typical roles" (Diekman and Eagly 2000, p. 1172). Aligned with the societal roles of the sexes, men are associated with the greater power of the employment role and status, and women with the less powerful status of the domestic role. Consequently, communality is perceived as a typically female attribute, while agency is commonly perceived as being a male attribute (Eagly and Wood 1999, 2012; Koenig et al. 2011).

In the workplace, perception of women's communality is perceived as a predisposition for success at female-typed careers and as an obstacle in male dominated occupations or leadership positions. Moreover, the female communality stereotype can lead to a benevolent sexism towards women comprising "putatively positive beliefs and behaviors toward women that serve to undermine their status" (Rudman and Phelan 2007, p. 24). Benevolent sexism can manifest in the patronizing behaviors toward female colleagues as well as low expectations and standards for women's excellence and less tangible rewards in male dominated occupations. One of the strategies for women to be accepted and valued in the male dominated occupations and positions is to "actively disconfirm the female gender stereotype by acting 'more like men"' (ibid., p. 28).

\section{Gender as an interactive process}

Although social beliefs and structural conditions constrain individual choices, individuals are actively engaged in the ongoing process of the (re-)production of gender stereotypes in their everyday interactions. Accordingly, gender is not what individuals have but what they do. The construct of 'doing gender' was introduced by West and Zimmerman (1987, p. 129): "[...] gender is not a set of traits, nor a variable, nor a role, but the product of social doings of some sort". In social interactions individuals act as a member of a sex category, performing themselves in virtually any activity as a woman or man while "their incumbency in one or the other sex category can be used to legitimate or discredit their other activities" (ibid., p. 136). At the same time, 'doing gender' means "to engage in behavior at the risk of gender assessment" (ibid.) and penalties, if an individual fails to act out his or her gender appropriately (Heilman and Parks-Stamm 2007). Rudman and Phelan (2007) discuss a variety of career-related backlash effects for women who present themselves not in accordance with gender stereotypes for being female, because the violation of prescriptive stereotypes "tends to boomerang so that actors suffer negative consequences for stereotype disconfirmation” (ibid., p. 38). Backlash effects for non-stereotypical behaviors thus contribute to gender inequalities and to the reproduction of gender stereotypical career pathways.

\section{Institutionalization of gender}

The culture of an organization is not gender neutral but is constructed along lines of gender. According to Dainty et al. (2000, p. 241) "the culture of an organization describes 
the unique way in which people act and interact within it". Gendering in organizational culture is described in Acker's Theory of Gendered Organizations (1990). This theory postulates five interacting processes of gendering in organizations. First, gendered divisions of labor that keep the technology in men's control and maintain "the definition of skilled work as men's work and unskilled work as women's work" (ibid., p. 146). Second, gendered construction of symbols and images that associate leadership with masculine traits. Third, (re-)production of social culture in which "men are the actors, women the emotional support" (ibid.). Fourth, (re-)production of gender identity through an individual choice of self-presentation as "a gendered member of an organization" (ibid.). Fifth, constitution of social structures and organizational logic, based on an underlying process of gendering. Through gendered organizational culture women are often disadvantaged via having a less powerful position and "stranger" status in male-dominated institutions and career fields (Acker 2006, 2008).

The women in male dominated occupations are not only disadvantaged through the gendered organizational culture, but also through their numerical minority status in occupations with a numerical dominance of male coworkers. Kanter (1977) suggests that the proportional composition of different social groups shapes interactional dynamics between the 'dominants' (numerical majority group) and the 'tokens' (numerical minority group). According to this conceptual framework, 'tokens' experience high visibility (i.e., they are aware of their underrepresentation), exaggeration of their differences compared to the dominant group (polarization), and assimilation pressure "to fit preexisting generalizations about their social type" (ibid., p. 965).

\section{State of research}

\section{Women in gender-atypical careers}

A number of studies have analyzed the underrepresentation of women in the construction industry, showing that the masculine image of construction affects women's decision to enter a career and/or to stay in a construction profession (Bennett et al. 1999; Dainty et al. 2000; Gale 1994; Yean Yng Ling and Yeu Pei Poh 2004). Among external barriers for women to enter a career in construction were women's perception of the competitive nature of the construction industry, time-consuming working conditions interfering with their family obligations and sexist attitudes towards women's abilities in construction (Dainty et al. 2000; Gale 1994; Yean Yng Ling and Yeu Pei Poh 2004). Additionally, women's individual attributes and traits were found to hinder their decision to enter a career in the construction industry, such as: lack of self-confidence in their own professional skills and their assertiveness in interactions with male counterparts, fear of not being able to "direct, supervise and coordinate the work of male subordinates", and perception of the pressure to assimilate to the 'male culture' (Yean Yng Ling and Yeu Pei Poh 2004, p. 435). Women who overcome the external and internal barriers and enter the pipeline of gender-atypical career fields were found to face a number of challenges in male dominated workplaces. In accordance with Kanter's (1977) framework of tokenism a study on women's experience of non-traditional employment in the UK has shown that women have to deal with high visibility and an outsider role or "accept some form of 'role entrapment' by adopting restricted and often caricatured roles within the system" (Whittock 2002, p. 454). 
In line with this, studies on the organizational culture of the engineering sector have shown that the gendering process starts within the educational institutions where "the culture and structure of the engineering education system has been designed for a male audience" (Powell et al. 2004, p. 21). Moreover, the masculine culture of engineering remains despite the increasing number of women in engineering, because female engineers assimilate to gendered organizational culture reinforcing the masculine image of the engineering profession (Powell et al. 2006). Likewise, Etzkowitz et al. (2000, p. 109) suggest that an increase of women in science and engineering departments, by itself, does not result in improved conditions for women's careers, because women are still underrepresented in powerful faculty positions within these fields. Moreover, even women with a faculty position reported lack of self-confidence to advocate for young female students within their departments. Thus, despite the increasing number of female students in gender-atypical study fields, "organizational structure within units, and the divisions they engender, continue to isolate women” (ibid., p. 111).

\section{Gender segregation in apprenticeship programs}

Research on gender segregation in apprenticeship programs is rare in the international context. A UK study reported that youth aged 14-15 years old were aware of gender stereotypes and classified occupations as 'female' or 'male' based on gender stereotypical attributes associated with an occupation (Fuller et al. 2005, p. 305f.; Fuller and Unwin 2013, p. 18). Interestingly, noticeably more young women compared to young men were considering learning a gender-atypical job. They were, however, concerned about how they would be treated in the male dominated professional fields. The main obstacle for women who were tempted to proceed with a gender-atypical career choice was the lack of practical information about job requirements (Beck et al. 2006; Fuller et al. 2005; Fuller and Unwin 2013).

Moreover, Fuller et al. (2005) reported findings with respect to employers' decisionmaking arguments related to apprenticeship training in the gender-atypical career fields. The results showed that employers in firms with less than 250 employees and from fields that do not have a shortage of trainees were not motivated to encourage applications from the under-represented group nor to "monitor their application and recruitment processes in terms of gender", while they agreed on the notion that "the non-traditional sex does not get enough career information" (ibid., p. 304). In addition, the findings revealed employers' gender stereotypes with respect to the 'natural' abilities and affinities of the sexes for a sex-matching occupation type (e.g., females' lack of physical strength) and employers' anticipation of additional costs to accommodate the 'other' sex in the workplace environment (e.g., separate washrooms). Particularly employers from the male dominated professional fields anticipated that "it is easier to train the traditional sex" (ibid., p. 304f.).

In the context of Switzerland, some studies have addressed gender segregation in VET programs. Pfister-Giauque and Flamigni (2009) reported findings about VET students who choose an occupation in which their own gender is in a minority, so called 'pioneers' (ibid., p. 2). Although the 18 interviewed VET teachers found specific teaching approaches for pioneers unnecessary, the researchers noticed "that they [the teachers] systematically resorted to using gender stereotypes when describing pioneers. [...]" 
However, they pointed out that "the commonly shared, stereotypical view of male and female pioneers as young, gifted, motivated people with good academic capabilities does not lead to the introduction of specific educational tools"(ibid., p. 7). Another Swiss study highlights the importance of the trainer's role during VET for young apprenticesindependent of the students' own gender. Students' identity is influenced by the way "[...] the apprentice is considered by colleagues in the company" and "the trainers play their model role" (Masdonati and Lamamra 2009, p. 12). Based on their research Masdonati and Lamamra recommend that programs "[...] sensitize trainers and company colleagues to the relational issues of VET" (ibid., p. 13). Wehner et al. (2016) interviewed young women and men about their gender-atypical career choice in a retrospective manner. The researchers concluded from the interviews that youngsters who have made a gender-atypical career choice often have greater abilities than their peers. They therefore summarized that there is still a need for more capacity and resources to learn a gender-atypical job than a job that is not segregated in terms of gender.

\section{Focus of the study}

\section{Research questions of the study}

To summarize the theoretical framework of our study, we view gender as "a multilevel system" (Correll et al. 2007, p. 4) characterized by gendered individuals inhabiting gendered positions in society and shaping their everyday interactions in those positions in accordance with the gendered expectations. The persistence of horizontal and vertical gender segregation in the workplace can, thus, be seen as an entanglement of psychological, social, structural and institutional factors.

The empirical evidence of research on women in the STEM apprenticeship and career fields suggests that the 'masculine culture' of STEM education and career fields can enlarge the leaks, causing the drop-out of women from the STEM-pipeline. However, previous research has mostly focused either on young people before entering vocational education or on women's experience after enrollment in STEM graduate studies or career fields. Little is known about young women who are actually enrolled in STEM VET at secondary schools. Moreover, studies addressing women's experience in genderatypical tracks of VET in Switzerland are lacking. In order to overcome this research gap our study addresses the following research questions:

Research Question 1 How do young women enrolled in VET in Swiss secondary schools experience being female in traditionally male-dominated professions?

Research Question 2 How do young women cope with their experiences in maledominated career fields during their VET?

As the focus of our study is young women in VET at secondary schools in Switzerland, the Swiss apprenticeship system will be described in what follows.

\section{The apprenticeship system in Switzerland}

The youth unemployment rate in Switzerland is one of the lowest among the OECD countries (OECD 2012). This might be partly due to the benefits of the Swiss apprenticeship system, in which about two-thirds of all young people enroll after completing their 
compulsory studies. Nearly another $40 \%$ of the youngsters who complete compulsory school attend grammar school (so-called Gymnasium in German), which prepares them to further education such as university. The remainder enroll either in entirely schoolbased forms of education or pursue no form of post-compulsory education, ranking Switzerland ahead of other OECD countries in terms of the percentage of the 16 years old and above attending school [e.g., (Muehlemann et al. 2009)].

In Switzerland, an apprenticeship is a 3-4 years long dual educational program that combines vocational education at school with on-the-job training in a company. There are some 230 different training occupations to choose from. Vocational education amounts to 1 or 2 days per week in a public school that provides general education, as well as occupation-related theoretical knowledge (school-based learning). The rest of the week, the apprentice receives paid formal training at the workplace under the supervision of certified staff (work-based learning). In big firms this certified staff is supported by HR professionals. In small firms the supervisors of the apprentices are enrolled in both roles (ibid.).

There are exams at school throughout the training period and an extensive final exam at the end of the apprenticeship. Successful graduates earn a diploma recognized throughout Switzerland that attests professional qualification to perform skilled work in the respective occupation (ibid.).

Closer analysis of VET programs in terms of gender reveals major disparities from program to program. Indeed, young women tend to be concentrated in areas relating to health, social care and personal services, while young men are much more prominent in technical areas, construction and mechanics (Pfister-Giauque and Flamigni 2009). This gender segregation continues when they enter the job market.

\section{Methods}

The analysis of experiences of young women in STEM VET was part of the research project Gender atypical career choices of young women (2010-2013), a project embedded in the Swiss National Science Foundation's National Research Program on 'Gender Equality' (www.nfp60.ch). The research project foresaw a mix method approach, which combined qualitative and quantitative data collection. The quantitative data was gathered throughout the first research phase, in which about 4000 students had to fill out a standardized questionnaire addressing their career choice. The students came from 42 Swiss-German high schools and 26 Swiss vocational schools. In a second research phase, qualitative data were collected during interviews with selected female students from the first phase. These interviews took place with 16 female Swiss-German high-school students and 71 female students attending vocational schools that had made a STEM career choice.

\section{Participants and data}

Our analysis is based on the qualitative sample. The data originated from semi-structured interviews with the 71 young women who had chosen a STEM career and were enrolled in VET in Swiss secondary schools (Makarova et al. 2012). The interviews were conducted by telephone in spring 2012. The selective sample comprised women in the following professional fields: technology and engineering $(\mathrm{N}=42,59 \%$, e.g., 
draftswoman) informatics ( $\mathrm{N}=18,26 \%$, e.g., computer scientist), mechanical professions ( $\mathrm{N}=8,11 \%$, e.g., automation engineer), and construction $(\mathrm{N}=3,4 \%$, e.g., carpenter) (Aeschlimann et al. 2015a). The four fields have a much smaller proportion of women than many other STEM fields. They are all characterized by less than $30 \%$ female workers and therefore represent gender-atypical career fields for young women (SFO 2010, population census). ${ }^{1}$

At the time, 20 of these young women were in their first, 19 in their second, 22 in their third and 10 in the last year of the VET. The women were 19 years old on average (SD 1.66). The parents of these young women represented a range of socio-economic status: $9.6 \%$ of the mothers had completed compulsory school as their highest level, but only $1.4 \%$ of the fathers. The majority of mothers had obtained an apprenticeship certificate $61.6 \%$, whereas $37.0 \%$ of the fathers had obtained this. Moreover, $12.3 \%$ of the mothers and $31.1 \%$ of the fathers had obtained a middle-level education. Only a few mothers $(2.7 \%)$ and $11 \%$ of the fathers had had a university-level education. Some women did not know the educational level of their parents (13.8 \% mothers; $19.5 \%$ fathers).

All interviews used the same questions and were pilot tested. The women were asked: "What experiences addressing you as a female in a gender-atypical career field have you had in your training company and in your vocational school?". As part of the high interest in dealing with their experiences, they were also asked about strategies: "Do you apply specific strategies in adjusting to the male-dominated educational and professional field?".

\section{Data analysis}

The interviews were transcribed verbatim, checked for errors and analyzed according the qualitative content analysis (Kuckartz 2012; Mayring 2008). Thus, data were summarized, segmented and patterned by a category scheme that was deductively determined, but also inductively enlarged according to the empirical material (using MAXQDA 11 software). The main concepts of this approach are categories that are defined elements of analysis. The categories have a certain degree of intricacy, are clearly defined, and are usually illustrated with code anchors (statement examples). The construction of categories not only depends on the researcher's previous knowledge, but also on the research focus of the study. If the categories are developed on the basis of previous knowledge or theory, they are formed in a deductive way; if they are developed on the basis of empirical material, they are formed in an inductive way. In such a systematic study, categories may be further processed in a second quantitative step. In our analyses, categories have been sorted out according to their frequency of occurrence in empirical material. In such a procedure that deals with categories, qualitative analyses are conducted first, whereas the second step consists of quantitative procedures which, in a third step, need to be interpreted qualitatively again (Mayring 2011, p. 5).

The interrater reliability was tested on 14 of 71 transcripts. Two researchers independently coded the 14 transcripts and compared the codes by discussing the similarities and differences in their coding strategy in order to maximize intercoder reliability.

\footnotetext{
${ }^{1}$ In Switzerland the field of technology and engineering employed about $16 \%$ female workers, whereas the fields of informatics, mechanics, and construction employed about 11, 3, and $1 \%$ women, respectively (SFO 2010, population census).
} 
After ongoing discussions between the coders, an interrater reliability of $75 \%$ could be regarded as solid. As the interviews were conducted in Swiss German (mother tongue dialect), the transcripts were later translated into Standard German (official written language). For the purpose of this article they were translated into English. The category scheme is shown in Table 1 . The findings are presented in the next section.

\section{Results}

The research questions of the study ("Research questions of the study" section) structure the "Results" section. First, we report on the experiences of young women who enrolled in VET in STEM fields. Second, we describe strategies these young women use in adjusting to their experiences in male-dominated professional fields.

\section{Young women's experiences in STEM vocational education and training}

Interviews with young women enrolled in VET in a STEM field revealed that being female in a male-dominated educational and professional environment was differently addressed by classmates at school and co-workers in the training company. Four different types of referring to the female sex within both realms - the training company and

Table 1 Category scheme

\begin{tabular}{|c|c|c|}
\hline Category & Content & Code anchors \\
\hline \multicolumn{3}{|c|}{ Women's experiences } \\
\hline Wrong sex & $\begin{array}{l}\text { References to women's perception of feeling } \\
\text { out of place }\end{array}$ & $\begin{array}{l}\text { Experience of differentiation in terms of being } \\
\text { in the wrong job, misogynist statements, } \\
\text { gender stereotypical expectations, custom- } \\
\text { ers have less trust in the women's expertise } \\
\text { and skills }\end{array}$ \\
\hline Exotic sex & $\begin{array}{l}\text { References to women's minority status in } \\
\text { the male-dominated school and work- } \\
\text { place }\end{array}$ & $\begin{array}{l}\text { Experience of underlining the underrepre- } \\
\text { sentation of women (e.g., teachers' explicit } \\
\text { naming of women within classroom) }\end{array}$ \\
\hline Archetypal sex & $\begin{array}{l}\text { References to women's differences com- } \\
\text { pared to men based on stereotypical } \\
\text { attribution of'nature' of sexes }\end{array}$ & $\begin{array}{l}\text { Challenges in terms of gendered prejudices, } \\
\text { gendered division of labor within the work } \\
\text { field (e.g., office work versus construction } \\
\text { site) }\end{array}$ \\
\hline Weak sex & $\begin{array}{l}\text { References to women's 'deficits' in terms of } \\
\text { professional tasks performance }\end{array}$ & $\begin{array}{l}\text { Experience of discrimination in terms of plac- } \\
\text { ing emphasis on the weakness (e.g., physical } \\
\text { differences) }\end{array}$ \\
\hline \multicolumn{3}{|c|}{ Women's adjustment strategies } \\
\hline Resilience & $\begin{array}{l}\text { References to women's capability of resist- } \\
\text { ance }\end{array}$ & $\begin{array}{l}\text { Thick skin, constancy, authority, self-confi- } \\
\text { dence, cheeky behavior, persistence, asser- } \\
\text { tiveness, self assurance, speak out }\end{array}$ \\
\hline Assimilation & References to women's familiarization & $\begin{array}{l}\text { High lightening self-reported masculinity } \\
\text { in behavior, in appearance and in leisure } \\
\text { activities, negating feelings and emotions, } \\
\text { male peer group, hide femininity, forceful } \\
\text { discussion }\end{array}$ \\
\hline Excellence & $\begin{array}{l}\text { References to women's high performance } \\
\text { and engagement }\end{array}$ & $\begin{array}{l}\text { High effort, efficacy, ambitiousness, proof } \\
\text { potential, persuasiveness, hard work }\end{array}$ \\
\hline Avoidance & References to women's avoidance tactics & $\begin{array}{l}\text { Invisibility, gender neutral appearance, igno- } \\
\text { rance of offending actions, immobility in } \\
\text { the workplace, ignore discriminatory patter, } \\
\text { avoid workplaces such as the construction } \\
\text { site, turn a deaf ear, paying selective atten- } \\
\text { tion }\end{array}$ \\
\hline
\end{tabular}


Table 2 Frequencies of codes within the category "women's experiences"

\begin{tabular}{lccc}
\hline Category & Training company & Vocational school & Total \\
\hline Wrong sex & 16 & 2 & 18 \\
Exotic sex & 7 & 5 & 12 \\
Archetypal sex & 9 & 2 & 11 \\
Weak sex & 7 & 1 & 8 \\
Total & 39 & 10 & 49 \\
\hline
\end{tabular}

the vocational school-were identified and coded along four categories: wrong sex, weak sex, exotic sex and archetypal sex (Table 2). ${ }^{2}$

Almost half of the interviewed women $\mathrm{N}=31$ (43.6 \%) encountered gendering processes within their VET. Overall, 49 codes were assigned to young women's experiences. However, young women experienced gender discrimination about four times more often in the training company (39 statements) than in the vocational school (10 statements). Among the four categories of experiencing being female in a male-dominated professional environment, the category wrong sex is the most prominent one (18 statements), followed by the category exotic sex (12 statements), archetypal sex (11 statements), and weak sex (8 statements) (Table 2).

The content of the four categories can be described as follows:

Wrong sex: The female vocational students were given the impression that, as a woman, they were in the wrong professional field. The women described misogynist conversations among co-workers, gender stereotypical expectations of their superiors, or too litthe trust in their professional expertise and skills on the part of customers. The young women, however, were distinctly more often confronted with this type of discrimination in the training companies (16 statements) compared to the vocational schools (2 statements) (Table 2). One of the young women working in a construction company during her vocational training remembered:

"In the professional world it was a little bit like, when you go on a construction site, the first remark is, oh there's a woman, she can't do anything anyway. When you then have to tell the construction workers something, they don't take you so seriously; that is a bit difficult" (ID_3945).

Another female student learning to be an auto-mechanic described her experience during vocational training:

"One sometimes hears misogynistic stuff and especially when one works in the assembly room, that's just part of it that certain things are being said" (ID_3837).

Exotic sex. In the training company (7 statements) and in the vocational school (5 statements) young women experienced their 'minority status' within their professional field in an unfavorable way. Through the explicit naming of the female sex, the young women were reminded that as women they are regarded as exotic in a male domain.

\footnotetext{
${ }^{2}$ We use the label "sex" along with the identified categories in our data based on the West and Zimmerman (1987, p. 127) conceptualization of 'sex category': "Placement in a sex category is achieved through application of the sex criteria, but in everyday life, categorization is established and sustained by the socially required identificatory displays that proclaim one's membership in one or the other category".
} 
Such experiences were reported with similar frequency within the training company and within the vocational school. One young woman who was trained for a career in informatics described her experiences thus:

"I always have to rotate to other departments in the company and then I have to apply for those positions. And at each interview the trainer says: 'And since you are a woman...' I couldn't take this to heart, otherwise it would have probably have crushed me" (ID_3481).

Likewise another young woman who had chosen an informatics profession remembered:

"What is just disturbing, is that ... the teachers always refer to a man [as a professional] and then at the end: 'We are very excited that women are also present,' they always underline this and that is sometimes a bit annoying" (ID_4329).

Archetypal sex. Some young women noticed that their professional potential was reduced through the stereotypical attribution of 'natural' female abilities. The young women mentioned this type of discrimination in the training companies more often (9 statements) than in the vocational schools (2 statements) (Table 2). Especially in the training company the division of labor was more often separated along gender lines. One of the women interviewed in the construction field commented on this:

"In the office ... there are, I believe, now more women than men, but especially in construction management for example, when you execute what you draw, then it is still quite a bit less common to see women on the construction site who lead this afterwards" (ID_4290).

In line with this, another young woman in construction training recalled:

"When I'm with the boss on a construction site and we meet business partners that don't know me yet, then it can happen that he is asked if he has brought his secretary along" (ID_3685).

Weak sex: The young women interviewed perceived that being female was interpreted as being weak physically. The young women experienced this type of discrimination mainly in the training companies (7 statements) compared to the vocational schools (1 statement) (Table 2). Young women's 'nature' and their appearance were often accentuated by co-workers in the training companies via exaggerated offers of support or in discriminatory statements about their 'delicate' constitution. One young women in construction training remembered:

"On the construction site mostly men are around and when you come to the construction site as a woman, you are first looked at with a bit of a smile, then maybe one is whistled at and when you can't climb up some place in order to measure [...], then you get a ladder [...], and then you hear stupid comments like 'Should we lift her up?' [in an ironic tone] or those kinds of comments" (ID_4453).

In summary the analysis of the young women's experiences in the VET Swiss schools and the training companies shows that being female in a male-dominated professional environment was frequently associated with discriminatory statements. Without 
exception, the training company environment was more discriminatory than the school environment.

\section{Young women's adjustment strategies}

With respect to the second research question, the interviews revealed four different strategies young women apply in order to cope with gender specific experiences within both the training company and the vocational training school. These strategies were coded along four categories: excellence, resilience, assimilation and avoidance (Table 3).

Of the 71 women interviewed, 27 (38 \%) described their strategies for adjusting to the male-dominated professional environment. Overall, 40 codes were assigned to the young women's adjustment strategies in professional training and school. The interviewees mentioned their strategies more often with respect to their experiences in the training company compared to their experiences in the vocational school. Among the four categories of adjustment strategies the strategy resilience was the most frequent (15 statements), followed by assimilation (10 statements), avoidance (7 statements), and excellence (Table 3).

The content of the four categories is described in what follows:

Resilience was the most frequent strategy young women used to assert themselves in male-dominated professions. In order to adjust to the male-dominated organizational culture young women were forced to express their persistence and their perseverance. The female students applied this strategy particularly often in the training company. One of the young women in the construction field described her strategy as follows:

"I just try to appear extremely steadfast. Because appearance is the key. [...] That's really when you bring a certain authority with you and a certain healthy self-confidence, then that works and then that's also totally accepted" (ID_4453).

Another young women who was trained as a carpenter recalled:

"I simply try to assert myself a bit against those men, in order to show that just because I'm a woman it doesn't mean that I just sit quietly in the corner and tolerate everything and that I also push back a little" (ID_4332).

Assimilation was a further strategy applied by young women in order to adjust to the male-dominated professional culture in their work and school environment. The female students reported negating or partially toning down their female appearance. In contrast to other adjustment strategies, this approach was used more often in the vocational

Table 3 Frequencies of codes within the category 'women's strategies'

\begin{tabular}{lccc}
\hline Category & Training company & Vocational school & Total \\
\hline Resilience & 12 & 3 & 15 \\
Assimilation & 1 & 9 & 10 \\
Excellence & 6 & 2 & 8 \\
Avoidance & 6 & 1 & 7 \\
Total & 25 & 15 & 40 \\
\hline
\end{tabular}


school. A young woman trained as a polymechanic mentioned that it is easier for young women who are less feminine to fit in:

"I am just naturally [...] rather not a typical girl and therefore I don't have to make much of an effort so that I really fit in there" (ID_3155).

Another young woman trained for a career in informatics described her strategy as follows:

"Yes, you maybe adjust in a certain sense a little bit. In terms of manners and such" (ID_4317).

Excellence. The young women recalled that based on the under-representation of female colleagues in their professional field they are constantly subjected to attention, which some of them interpreted as performance pressure and performance drive. This strategy was mentioned three times more often in the context of the training company compared to the vocational school. One young woman who had chosen an informatics profession said:

"Just to be always efficient and if possible to execute everything correctly" (ID_3299).

Likewise another young woman trained as an electrician said:

"In the school I basically make sure that I perform well so that [...] afterwards the stereotype never develops that women and technology are just not compatible. I simply try to prove myself, so that those comments don't even occur" (ID_4442).

Avoidance was a strategy of young women consciously avoiding burdensome situations or trying to ignore them completely. The avoidance of uncomfortable situations was more common in the training company than in the vocational school. One woman who had chosen a profession within the construction field described her strategy as:

"I don't necessarily go on the construction site every day, because I'd rather send someone else to the construction site while I make the plans and draw. I just leave it like that then. I don't stand up against it" (ID_3913).

In line with this, another young woman trained as an auto mechanic said:

"You simply sometimes close your ears and work by yourself; just because I am now in the workshop the only one and in the class, too" (ID_4405).

In summary our results have demonstrated that it is a highly challenging process for young women to fit in within a male-dominated professional environment. What is clear is that they need to have considerable resilience in handling gender discriminatory statements. At the same time, they have to be able to find their place and subordinate themselves in the predominantly masculine organizational culture, to show high performance commitment and ignore uncomfortable situations.

\section{Discussion and conclusion}

The results of our study deliver strong support for the persistence of gender stereotypic beliefs about young women and their professional competencies in apprenticeship programs in male dominated career fields. Moreover, the study provides insight into the process of 'doing gender' in STEM VET by uncovering different mechanisms 
and symbolic actions which contribute to the (re-)production of a masculine culture in STEM professions.

The findings of the study illustrate that young women in vocational school and training are perceived in accordance with the prevalent societal stereotype of the female role (Diekman and Eagly 2000; Eagly and Wood 2011). Thus, during their apprenticeship young women anticipate gendered division of labor and a subordinate position of female professionals (Acker 1990, p. 146) based on their experience of being ascribed to the 'wrong sex', the 'weak sex', or the 'archetypal sex.' Thus, the young women's experience of being addressed as less skilled or naturally less capable of performing a task without the help of male colleagues discriminates against women as 'second class' professionals or segregates them to particular tasks within the field. These findings show that despite the increasing participation of women in the workforce the descriptive stereotype content of the female societal role has not been changing apace in male dominated career fields, prescribing "that women should differ from men in ways that negatively reflect on their ability to perform high-powered jobs" (Rudman and Phelan 2007, p. 25).

The perception of sexist attitudes towards their own abilities in the gender-atypical career field may be one of the reasons why young women do not enter a career they were trained and educated for (Yean Yng Ling and Yeu Pei Poh 2004, p. 435). In order to combat the gender stereotypical culture of their professional field and to prove their image as 'first class' professionals, young women choose the strategy of excelling among their male counterparts. However, some of the young women accept their status by avoiding performance situations and choosing to stick to their 'role'. These results support the notion that being engaged in 'doing gender' means being involved in gender assessment (West and Zimmerman 1987, p. 136) and anticipating penalties or backlash effects for not acting in appropriateness with shared gender stereotypes (Heilman and ParksStamm 2007; Rudman and Phelan 2007). Especially because the high visibility of women in male dominated career fields leads to performance pressure among the 'female minority group' or to "the tokens' role entrapment" (Kanter 1977, p. 965). In this vein, Whittock (2002, p. 451) suggested that women "respond to heightened visibility with either overachievement or underachievement, each of which can present obstacles to further advancement".

Moreover, high visibility based on young women's experience of being the 'exotic sex' puts psychological pressure on them, requiring them to adjust to the masculine culture of their future professional field. Thus, to overcome the status of a "foreigner" (Acker 2006, 2008) and to participate equally in the "gentleman's club", which is "polite and civilized and not hostile to women as long as they conform to a clear role stereotype" (Gale 1994, p. 11), young women have to assimilate their self-presentation and appearance accordingly (Kanter 1977, p. 965; Whittock 2002, p. 451). It is interesting that both the experience of being exotic and the strategy of assimilating to the gender-atypical culture of the professional field were more strongly manifested within the school environment of the VET. This finding suggests that, like STEM tracks in tertiary education, STEM professions in secondary vocational education are designed for men (Etzkowitz et al. 2000). The perceived pressure to assimilate to the 'male culture' of their professional field can be the reason why young women do not proceed with a STEM career after finishing their professional education (Yean Yng Ling and Yeu Pei Poh 2004, p. 435). Moreover, 
the perception of the 'masculine' traits of the profession makes it difficult for young women to consider learning a 'male' profession (Beck et al. 2006; Fuller et al. 2005; Fuller and Unwin 2013). As the "matching sex type" of an occupation has a decisive impact in the process of career choice (Gottfredson 2002, p. 93), our findings suggest that the mismatch between the sex type of the profession and self-image can discourage young women from continuing their gender-atypical career path after they have completed their VET. These findings support the existing empirical evidence suggesting that the masculine image of STEM career fields affects women's decision to enter a career and/or to stay in a profession (Bennett et al. 1999, Dainty et al. 2000; Gale 1994; Yean Yng Ling and Yeu Pei Poh 2004).

Furthermore, our findings showed that gender stereotypic beliefs and attributions were particularly pronounced within the training companies where young women first encounter professional experience during the VET. This result corresponds to findings reported by Fuller et al. (2005) revealing employers' gender stereotypes with respect to the 'natural' abilities and affinities of the sexes for a sex-matching occupation type. In this vein, our findings also support the notion that more capacity and resources are needed to be trained in a gender-atypical profession (Wehner et al. 2016). However, while young women experience open discrimination in interactions with their male coworkers in the training companies (e.g., in misogynist comments and jokes), they experience benevolent sexism from their teachers and supervisors, who positively highlight the fact that female students want to pursue careers in STEM fields but at the same time patronize them or adjust professional standards (Rudman and Phelan 2007).

It was also shown that to combat discrimination in the workplace young women most frequently applied a resilience strategy. The resilience of these young women was based on high assertiveness, steadfastness, and the ability to push back, resembling the image "of successful, forceful masculinity" (Acker 1990, p. 146), acting "more like men" (Rudman and Phelan 2007, p. 28). This finding is in line with research suggesting that women who are successful in gender-atypical careers converge toward the masculine image of the profession and reinforce its masculine culture (Dainty et al. 2000; Gale 1994; Powell et al. 2006). Since this strategy was the most frequent one used among young women, our findings support the notion that the increment of female professionals in STEM fields alone will not fundamentally improve conditions for women's careers, because women who are successful in male-dominated career fields tend to preserve the masculine image and culture of their field (Etzkowitz et al. 2000).

Overall, the study illustrates the everyday experience of young women searching for a balance between doing and undoing gender in their STEM education and training in Swiss vocational schools. It highlights the need to develop and implement actions to overcome the exclusion and discrimination of female students in STEM education and training in order to plug the leaks in the STEM pipeline.

\section{Implications for practitioners}

The findings of our study have important practical implications, as they uncover numerous external barriers for young women enrolled in VET to continue their STEM career. Thus, to overcome gender inequality in STEM career fields, more attention should be given to gender mainstreaming in VET education by “making women's as well as men's 
concerns and experiences an integral dimension of the design, implementation, monitoring and evaluation" (UN and ECOSOC 1997, p. 2) of educational and trainings settings.

Our study provides empirical evidence that within VET, training companies should be challenged more to combat sexism and gender discrimination in order to create an inclusive working environment for young women in gender-atypical careers. As human resource departments play a very important role in diversity management (Jabbour et al. 2011), they need to implement inclusive practices in order for different people to be able to work well together, to use everyone's skills more efficiently, and to take advantage of complementarities in individual skills and interests (OECD 2012, p. 2; Lazear and Oyer 2007, p. 38). This requires, first, understanding the process of (re-)production of gender inequalities within the organizational culture. Second, recognizing the gendering mechanisms and routings within the organizational culture and how they affect individual professional development. Third, making a proactive effort to realize diversity potential within gender segregated professional fields. Fourth, making the image of a STEM career more attractive to young women by increasing empathy for and appreciation of diversity within the workplace.

Furthermore, our results suggest that there should be more external support and training for HR-responsible staff in companies, particularly if these companies have no dedicated HR department that would monitor gender equality issues. Switzerland has a high number of small and medium-sized enterprises (SMEs) and, as Woodhams and Lupton suggest, these types of firms "often obtain their HR advice from non-specialist sources, e.g., their accountants, and therefore improved access and encouragement to take specialist advice may have positive outcomes" (2006 p. 93).

Overall, our study highlights the role of VET institutions in counterbalancing the existing gender bias in STEM careers and its decisive potential in promoting gender equality. However, our results also suggest that women's experiences in STEM VET needs to be further analyzed in future research.

\begin{abstract}
Authors' contribution
WH and EM conceived, designed and coordinated the study. BA participated in the design of the study and coordinated the data collection. She performed the analysis, interpreted the data and drafted the methodological and findings part of the manuscript. EM participated in the data analysis and the interpretation. She drafted the theoretical and discussion part of the manuscript. WH, EM and BA revised the whole manuscript. All authors contributed substantially to this work. All authors read and approved the final manuscript.
\end{abstract}

\title{
Authors' information
}

EM is a professor at the Centre for Teacher Education and the Department of Education at the University of Vienna. She studied educational sciences at the National Pedagogical University of Kiev, Ukraine, and at the University of Bern, Switzerland, where she received her PhD in Philosophical and Human Sciences in 2007 and earned the degree of Privatdozent in 2014. Her main research interests are acculturation, gender and career choice, and diversity in education.

BA is a senior researcher at the Swiss Federal Institute for Vocational Education and Training (SFIVET), Zollikofen, Switzerland. She studied educational sciences at the University of Bern, Switzerland, where she also received her Ph.D. in Philosophical and Human Sciences in 2014. Her research interests cover vocational choice process, educational inequalities, gender, transitions into, through and out of education, and VET.

WH was full professor of education and educational psychology at the University of Bern from 1991 until his retirement in 2015. He studied psychology at the University of Zürich, where he also received his Ph.D. in educational sciences in 1980 and earned the degree of Privatdozent in 1986. He specializes in research on schools and teaching, history and foundations of educational psychology and teacher professionalism.

\footnotetext{
Author details

1 Department of Education, Centre for Teacher Education, University of Vienna, Porzellangasse 4, 1090 Vienna, Austria.

2 Swiss Federal Institute for Vocational Education and Training, Kirchlindachstrasse 79, Postfach, 3052 Zollikofen, Switzerland. ${ }^{3}$ Department of Educational Psychology, Institute of Educational Science, University of Bern, Fabrikstraße 8 , 3012 Bern, Switzerland.
} 


\section{Acknowledgements}

The authors gratefully acknowledge the Swiss National Science Foundation for financial support of the study "Gender atypical careers of young women" (Grant no. 4060-129279). Furthermore, we would like to thank Irene Kriesi from the Swiss Federal Institute for Vocational and Educational Training in Switzerland (SFIVET) for her useful comments on an earlier draft of this paper.

\section{Competing interests}

The authors declare that they have no competing interests.

Received: 10 January 2016 Accepted: 14 January 2016

Published online: 01 February 2016

\section{References}

Acker J (1990) Hierarchies, jobs, bodies: a theory of gendered organizations. Gender Soc 4(2):139-158

Acker J (2006) Inequality regimes gender, class, and race in organizations. Gender Soc 20(4):441-464

Acker J (2008) Helpful men and feminist support: more than double strangeness. Gender Work Organ 15(3):288-293

Aeschlimann B, Herzog W, Makarova E (2015a) Frauen in MINT-Berufen: Retrospektive Wahrnehmung des mathematischnaturwissenschaftlichen Unterrichts auf der Sekundarstufe I. Zeitschrift für Bildungsforschung 5:37-49

Aeschlimann B, Herzog W, Makarova E (2015b) Studienpräferenzen von Gymnasiastinnen und Gymnasiasten: Wer entscheidet sich aus welchen Gründen für ein MINT-Studium? Schweizerische Zeitschrift für Bildungswissenschaft 37:285-300

Beck V, Fuller A, Unwin L (2006) Safety in stereotypes? The impact of gender and 'race' on young people's perceptions of their post compulsory education and labor market opportunities. Br Educ Res J 32(5):667-686

Beede D, Julian T, Langdon D, McKittrick G, Khan B, Doms M (2011) Women in STEM: a gender gap to innovation. U.S. department of commerce, economics and statistics administration, Washington

Bennett JF, Davidson MJ, Gale AW (1999) Women in construction: a comparative investigation into the expectations and experiences of female and male construction undergraduates and employees. Women Manag Rev 14(2):273-291

Burke RJ, Mattis MC (2007) Women and minorities in science, technology, engineering and mathematics: upping the numbers. Edward Elgar Publishing Limited, Cheltenham

Ceci SJ, Williams WM, Barnett SM (2009) Women's underrepresentation in science: sociocultural and biological considerations. Psychol Bull 135:218-261

Charles M (1992) Cross-national variation in occupational sex segregation. Am Sociol Rev 57:483-502

Correll SJ, Thébaud S, Benard S (2007) An introduction to the social psychology of gender. Adv Group Process 24:1-18

Dainty ARJ, Bagilhole BM, Neale RH (2000) A grounded theory of women's career under-achievement in large UK construction companies. Constr Manag Econ 18:239-250

Deaux K, LaFrance M (1998) Gender. In: Gilbert DT, Fiske ST, Lindzey G (eds) The handbook of social psychology. McGrawHill, New York, pp 788-828

Diekman AB, Eagly AH (2000) Stereotypes as dynamic constructs: women and men of the past, present, and future. Pers Soc Psychol Bull 26(10):1171-1188

Eagly AH, Wood W (1999) The origins of sex differences in human behavior. Evolved dispositions versus social roles. Am Psychol 54:408-423

Eagly A, Wood W (2011) Feminism and the evolution of sex differences and similarities. Sex Roles 64:758-767

Eagly A, Wood W (2012) Social role theory. In: van Lange P, Kruglanski A, Higgins ET (eds) Handbook of theories in social psychology. Sage Publications, Thousand Oaks, pp 458-476

Etzkowitz H, Kemelgor C, Uzzi B (2000) Athena unbound: the advancement of women in science and technology. Cambridge University Press, Cambridge

Fuller A, Unwin L (2013) Gender segregation, apprenticeship, and the raising of the participation age in England: are young women at a disadvantage? Available via http://www.llakes.org. Accessed 01 Dec 2015

Fuller A, Beck V, Unwin L (2005) The gendered nature of apprenticeship: employers' and young people's perspectives. Educ+ Train 47(4):298-311

Gale AW (1994) Women in non-traditional occupations: the construction industry. Women Manag Rev 9(2):3-14

Gottfredson LS (2002) Gottfredson's theory of circumscription, compromise, and self-creation. In: Brown D, Brooks L (eds) Career choice and development. Jossey-Bass, San Francisco, pp 85-148

Hadjar A, Aeschlimann B (2015) Gender role orientations, gendered interest in school subjects and vocational perspectives among male and female eight-graders in Switzerland. Educ Res 57:22-42

Heilman ME, Parks-Stamm EJ (2007) Gender stereotypes in the workplace: obstacles to women's career progress. Adv Group Process 24:47-77

Jabbour CJC, Gordono FS, Caldeira de Oliveira JH, Martinez JC, Oliveira JHC, Battistelle RAG (2011) Diversity management: challenges, benefits, and the role of human resource management in Brazilian organizations. Equal Divers Incl Int J 30(1):58-74

Jarman JR, Blackburn M, Racko G (2012) The dimensions of occupational gender segregation in industrial countries. Sociology 46:1003-1019

Kanter RM (1977) Some effects of proportions on group life: skewed sex ratios and responses to token women. Am J Sociol 82(5):965-990

Koenig A, Eagly A, Mitchell A, Ristikari T (2011) Are leader stereotypes masculine? A meta-analysis of three research paradigms. Psychol Bull 137(4):616-642

Kuckartz U (2012) Qualitative Inhaltsanalyse: Methoden, Praxis, Computerunterstützung. Weinheim 
Lazear EP, Oyer P (2007) Personnel economics. Working paper no 13480. National bureau of economic research, Cambridge

Makarova E, Herzog W, Vogt [Aeschlimann] B, Ignaczewska J (2012) Geschlechtsuntypische Berufs- und Studienwahlen bei jungen Frauen: Dokumentation und Ergebnisse der Projektphase 2 (Forschungsbericht Nr. 43), Universität Bern, Institut für Erziehungswissenschaft, Abteilung Pädagogische Psychologie, Bern

Masdonati J, Lamamra N (2009) Dropping out of vocational education and training: identity dynamics and realtional issues. VET Congress, Switzerland, pp 1-14

Mayring P (2008) Qualitative Inhaltsanalyse. Grundlagen und Techniken, 10th edn, Weinheim

Mayring P (2011) Kombination und Integration qualitativer und quantitativer Analysen. Forum Qual Sozialforschung 2(1):1-13

Muehlemann S, Wolter SC, Wüest A (2009) Apprenticeship training and the business cycle. Empir Res Vocat Educ Train 2:173-186

Nosek BA, Banaji MR, Greenwald AG (2002) Math = Male Me = Female, therefore Math $\neq$ Me". J Pers Soc Psychol 83(1):44-59

OECD (2009) Equally prepared for life? how 15-years-old boys and girls perform in school. OECD, Paris

OECD (2012) Closing the gender gap: act now. OECD, Paris

Pfister-Giauque B, Falmigni E (2009) Cultural diversity and gender in Swiss vocational and educational training (VET): identification and analysis of organizational and pedagogical arrangements to integrate diversity. Paper presented at the ECER, Vienna

Powell A, Bagilhole B, Neale R (2004) Does the engineering culture in UK higher education advance women's careers? Equal Oppor Int 23:21-38

Powell A, Bagilhole B, Dainty ARJ (2006) The problem of women's assimilation into UK engineering cultures: can critical mass work? Equal Oppor Int 25(8):688-699

Preston A (2004) Plugging leaks in the scientific workforce. Issues in Science \& Technology, pp 69-74

Rudman LA, Phelan JE (2007) Sex differences, sexism, and sex: the social psychology of gender from past to present. Adv Group Process 24:19-45

SKBF (2014) Swiss education report. Available via http://skbf-csre.ch/fileadmin/files/pdf/bildungsmonitoring/Swiss_Education_Report_2014.pdf. Accessed 5 May 2015

Solga H, Pfahl L (2009) Doing Gender im technisch-naturwissenschaftlichen Bereich. In: Milberg J (ed) Förderung des Nachwuchses in Technik und Naturwissenschaft. Springer-Verlag, Berlin, pp 155-219

Sousa-Poza A (2003) The Gender Wage Gap and Occupational Segregation in Switzerland, 1991-2001. Swiss I Sociol 29:399-415

Swiss Federal Statistical Office (SFO) 2010 Population Census/Communes-Ménages-Personnes 2000. Erwerbstätige nach Geschlecht und beruflicher Tätigkeit nach ISCO-88(COM). Available via http://www.bfs.admin.ch/bfs/portal/de/ index/infothek/erhebungen_quellen/blank/blank/vz/uebersicht.html. Accessed 25 Jun 2012

UN, ECOSOC (1997) Agreed Conclusions. 1997/2, Available via http://www.un.org/womenwatch/osagi/gmrolesmadtgenfp.htm. Accessed 27 Apr 2015

Wehner N, Schwiter K, Hupka-Brunner S, Maihofer A (2016) Geschlechtsungleichheiten in Ausbildungs- und Berufsverläufen junger Erwachsener in der Schweiz. Ergebnisse aus einer Mixed-Methods-Studie. In: Faulstich-Wieland H (ed) Berufsorientierung und Geschlecht. Beltz, Weinheim, pp 23-38

West C, Zimmerman DH (1987) Doing Gender. Gend Soc 1(2):125-151

Whittock M (2002) Women's experiences of non-traditional employment: is gender equality in this area a possibility? Constr Manag Econ 20:449-456

Woodhams C, Lupton B (2006) Gender-based equal opportunities policy and practice in small firms: the impact of HR professionals. Hum Resour Manag J 16(1):74-97

Yean Yng Ling F, Pei Poh Y (2004) Encouraging more female quantity surveying graduates to enter the construction industry in Singapore. Women Manag Rev 19:431-436

\section{Submit your manuscript to a SpringerOpen ${ }^{\circ}$ journal and benefit from:}

- Convenient online submission

- Rigorous peer review

- Immediate publication on acceptance

- Open access: articles freely available online

- High visibility within the field

- Retaining the copyright to your article

Submit your next manuscript at $\boldsymbol{\sim}$ springeropen.com 